\title{
Comparative Versus Noncomparative Sales Pitches: Impact On New Product Buying Behaviors And Moderating Role Of Buyer-Seller Relationship
}

Christian Dianoux, CEREFIGE, University of Lorraine, France Jean-Luc Herrmann, CEREFIGE, University of Lorraine, France Ridha Chakroun, IPAG Business School, IPAG Research Lab, France Sandrine Heitz-Spahn, CEREFIGE, University of Lorraine, France.

\begin{abstract}
The purpose of this research is to explore the effectiveness of Comparative Sales Pitches (CSPs) vs. NonComparative Sales Pitches [NCSPS] in terms of actual buying behavior of a new product. Using a wholesaler's telephone sales campaign, we performed a quasi-experimental study focusing on the actual ordering behavior for a new product of more than 4,200 pharmacists in response to a CSP (vs. an NCSP). The research shows that a CSP is more likely to generate a new product sales order than an equivalent NCSP. This positive effect manifests only when a relationship exists between the buyer and the seller. In addition, the results support the relational advantage of a regular buyer-seller relationship regardless of the type of sales pitch used. The findings should encourage managers and salespeople to consider CSPs as an effective selling tool for launching a new product, especially when a relationship with the buyer exists. This research provides a starting point for further research into CSP effects -an area in which limited research exists to date- to gain a better understanding of their boundary selling effectiveness.
\end{abstract}

Keywords: Comparative Sales Pitches; New Product Launching; Buyer-Seller Relationship; Actual Buying Behaviors

\section{INTRODUCTION}

omparisons between competing products or brands are frequently used in a selling context. More than 30 years ago, Golden $(1979$, p. 517) stated that "explicit comparisons between named competing brands have been made for centuries in personal selling."

Nearly concurrently, Weitz (1978) introduced a model of the process by which a salesperson influences a buyer's preferences to achieve better sales records, thereby establishing the critical importance of selling-strategy formulation for personal selling effectiveness. He conceptualizes selling strategies as having two components: definition of a strategic objective and formulation of a message to achieve that objective. Referring to advertising strategies, Weitz (1978, p. 505) identifies some potential strategic objectives such as "adding or deleting products from the customer's consideration set" and "altering customer's beliefs about the performance of the product in relation to competing products." Concerning message formulation, the existing comparative advertising literature (Miniard, Rose, Barone and Manning, 1993; Grewal, Kavanoor, Fem, Costley and Barnes, 1997) clearly supports the idea that explicit comparisons between competing products may achieve such objectives, and ultimately may enhance sales effectiveness.

Furthermore, according to the launch strategy and the new product performance literature, the ability to achieve a new product trial or adoption "will in a large measure be a function of the perceived relative advantage 
and/or the perceived compatibility of the innovation" against those of other products (Guiltinan, 1999, p.514). Communication with customers, especially information-based appeals demonstrating the differential benefits of the new product, can directly influence its perceived relative advantage and/or its perceived compatibility (e.g. Guiltinan, 1999; Lee and O'Connor, 2003; Chen, Shen and Chiu, 2007). Comparative sales pitches might therefore be decisive when trying to sell a new product.

Surprisingly, however, to the best of our knowledge, the effects of comparative versus noncomparative sales presentations on new product selling effectiveness remains a quite virgin field. Therefore, the purpose of the present research is to explore the effectiveness of Comparative Sales Pitches (CSPs) versus NonComparative Sales Pitches (NCSPs) on actual buying behaviors in the specific context in which a seller introduces a new product to a retailer.

In reference to the comparative advertising literature (Wilkie et Farris, 1975; Barry, 1993), we define CSPs as sales presentations in which the seller praises the product/brand sold and compares it with at least one identified (or named) competitor product/brand, and NCSPs as sales presentations in which the seller praises the product/brand sold without any mention of rival products/brands. Herein, "sales pitches" refer to the sales presentations (both comparative and noncomparative) used in a telephone sales campaign targeting pharmacists. The objective of this campaign was to place an initial order for a new product. Within that context, the current research investigates the moderating role of the existence (or nonexistence) of a relationship between the seller's and the buyer's companies. To achieve this aim, we focus on the actual ordering behaviors of more than 4,200 pharmacists involved in a quasiexperiment that records the results of a telephone sales campaign implemented by a wholesale distributor.

We organize the remainder of the article as follows. The next section provides a brief literature review of comparisons in selling strategies and new product launching as well as of comparative advertising efficacy, which leads to the development of our three hypotheses in the selling context of a new product. Then, we describe a quasiexperiment conducted in the naturalistic environment of a new product telesales campaign. After we present the results, we discuss the contributions and limitations of this work, which opens many avenues for further research.

\section{LITERATURE REVIEW AND HYPOTHESES DEVELOPMENT}

\section{Comparisons in Selling Strategies and New Product Launching}

Though comparisons between named competing products or brands have been used for centuries in personal selling (Golden, 1979), research on selling strategies thus far has not examined the effectiveness of using such comparisons in sales presentations.

An exception in the selling literature is Wagner, Klein and Keith (2001) investigation of selling strategies aimed to influence the structure of the professional buyer's decision, which does mention comparisons with competitors' products. The authors note that the summary-of-benefits and agenda selling strategies differ in several ways:

\footnotetext{
"In addition to the information about the target product's benefits, the salesperson using an agenda strategy encourages the buyer to use specific constraints to eliminate some products from consideration. Then, to ensure that buyers have the information they need to decide whether to adopt the suggested constraint, the salesperson provides information about the relevant attribute for all products still under consideration. In contrast, a summary-of-benefits strategy may occasionally refer to a competitor but does not typically provide detailed competitive information. The agenda strategy's sharing of information about competitors may be part of its advantage" (Wagner, Klein and Keith, 2001, p.293).
}

Using simulated sales calls, the authors show that agenda presentation strategies generate more favorable product evaluations, greater probabilities of being part of the consideration set, and greater probabilities of choice than more traditional summary-of-benefits presentation strategies. 
According to the new product performance literature, agenda selling strategies and comparative sales presentations might be of particular interest when launching new products.

Developing a conceptual framework linking launch strategies and tactics to the degree of product innovativeness, Guiltinan (1999) draws special attention to two characteristics of a new product that influence adoption: relative advantage and compatibility with values and experiences. There is empirical evidence that these two characteristics have the greatest direct influence on new product trial and adoption (Ostlund, 1974; Holak and Lehmann, 1990; Dhebar, 1995; Veryzer, 1998).

As highlighted by Guiltinan (1999, p.514), these two characteristics "are perceived and evaluated in a comparative fashion. Relative advantage depends on a positioning of the product's benefits against those of other products, and compatibility depends on a positioning of the product's fit with individuals' needs, values, and experiences/usage systems compared to the fit of other previously used products. Thus, the relative advantage and compatibility of a new product are judged against:

- $\quad$ Existing products in the same market for new entries or line additions into existing markets,

- $\quad$ Prior models/generations in the case of product enhancements, and,

- $\quad$ Product forms or categories previously used to meet comparable needs in the case of new-to-the-word products."

According to Guiltinan (1999), launch tactics can directly influence the perceived relative advantage and/or the perceived compatibility of a new product. The more the product is new and offers a high relative advantage, the more information-based promotion is required to influence the perceived relative benefits of the new product being promoted (Guiltinan, 1999; Chen, Shen and Chiu, 2007).

This is in line with the results presented by Lee and O'Connor (2003) in their study investigating the moderating role of product innovativeness in the relationship between communication strategy and new product performance. They found that functional ads, i.e. using informational, factual, rationale appeals to demonstrate the differential benefits of the new product, lead to higher performance (compared to emotional ads), when the product has clear advantages over other known products and has superior benefits for customers.

However, although some researchers have examined the effectiveness of selling strategies providing competitive information (Wagner, Klein and Keith, 2001) and the impact of advertising strategy based on informational appeals to demonstrate the differential benefits on new product performance (e.g. Guiltinan, 1999; Lee and O'Connor, 2003; Chen, Shen and Chiu, 2007), they do not specifically address the effectiveness of comparative presentations on new product sales.

In contrast, in the advertising literature many articles address the efficacy of using this type of comparison in an advertising context.

\section{The Efficacy of Comparative Advertising}

Since the seminal papers of Wilkie and Farris (1975) and Barry and Tremblay (1975), many studies have addressed the efficacy of comparative advertising (for a review, see Grewal et al., 1997), including numerous works measuring the specific impact of Comparative Advertising (CA) versus NonComparative Advertising (NCA). According to this literature, in diverse contexts (Stevenson and Swayne, 1988) and, notably, in conditions under which a newcomer or a low-market-share brand challenges the market leader, CA that mentions the leader is more effective than NCA in terms of the following:

- $\quad$ increased favorable attitudes toward the brand (Swinyard, 1981; Gotlieb and Sarel, 1991; Rose, Miniard, Barone, Manning, Till, 1993; Putrevu and Lord, 1994; Shao, Bao and Gray, 2004); and

- $\quad$ increased purchase intentions (Golden, 1979; Dröge, 1989; Pechmann and Stewart, 1990; Gotlieb and Sarel, 1991; Putrevu and Lord, 1994; Thomson and Hamilton, 2006 [when consumers use analytical processing]; Chang, 2007 [only for men in the context studied]; Beard, 2013 [according to practitionners]). 
Moreover, several authors have shown that comparative ads can enhance the assessment of the product's benefits relative to competitors and encourage consumers to evaluate a product relative to other products (Miniard et al., 1993; Rose et al., 1993).

Despite advertisers' interest in sales, and Grewal et al.'s (1997) call for such studies, there is still a dearth of studies focusing on the effects of comparative advertising on actual purchase behaviors. To the best of our knowledge, only two authors have attempted to address this critical question. Swinyard (1981) studied self-reported behaviors after exposure to different types of comparative and noncomparative ad campaigns of a store (Bobco's). Demirdjian (1983) examined coupon redemption rates at a $40 \%$ discount rate for the purchase of two brands of pen. In an interview for Advertising Age, he stated that comparative ads would generate at least a $20 \%$ increase in sales if properly done (McArthur and Cuneo, 2007). More recently, Hsieh, Blower, Li, Jain and Posavac (2012) do not quote any new research focusing on the effects of comparative advertising on purchase behaviors. They conclude from their literature review that "comparative advertising can have a significant influence on purchase behavior." (p.134).

With regard to the reasons explaining CA superiority, Dröge (1989) argues that CA more likely induces a central treatment, whereas NCA prompts recipients to engage in peripheral processing. Many other studies tracking the effects of CA on attention, message involvement, and memory provide consistent results (e.g., Muehling, Stoltmann and Grossbart, 1990; Pechmann and Stewart, 1990), if the advertised brand has low market share or if it is a new brand and the compared brand has a high share of the market. Pechmann and Esteban (1994) support the idea that CA, compared with NCA, stimulates message treatment such that persuasion occurs along the central route.

Not surprisingly, Grewal et al.'s (1997) meta-analysis supports the conclusion that CA induces greater elaboration and more central processing than NCA. With regard to NCA, comparative ads increase the number of message-related thoughts consumers generate in reaction to these ads. However, the direction of these messagerelated thoughts can be in support of or against the promoted brand. Thus, for this enhanced elaboration or processing to have a positive effect on purchase behaviors, consumers must consider the ad believable (e.g., Petty, Cacioppo and Schumann, 1983; MacInnis, Moorman and Jaworski, 1991; Meyers-Levy and Malaviya, 1999).

According to Grewal et al. (1997), comparative ads are less believable than noncomparative ads. More specifically the authors' meta-analysis results support that source credibility is more likely to be significant for noncomparative ads than for comparative ads. This apparent inconsistency (less believability but greater purchase intentions) is resolved when credibility is considered a moderator. As Grewal et al. note, first, comparative ads with enhanced credibility are not significantly less believable than noncomparative ads. Second, more credible comparative ads generate higher levels of intention to purchase the promoted brand.

\section{The Influence of the Buyer-Seller Relationship}

We now discuss research that addresses the relational (vs. discrete) exchange situation in which a seller encounters a potential buyer, in the context of considering credibility as a moderator. Depending on the nature of the buyer-seller encounter (Wagner, Klein and Kieth, 2003), this relational exchange situation may moderate the effectiveness of CSPs and NCSPs on buyers' purchasing behaviors.

Relationship marketing theory that consists of establishing, developing, and maintaining successful relational exchanges (Webster, 1992; Morgan and Hunt, 1994) is an established research stream traditionally distinguished from discrete transactions, which have a short duration perspective (Dwyer, Schurr and Oh, 1987). Beyond this classical dichotomous view, marketing relationships range on a continuum from pure discrete transactions (single sale), repeated transactions, long-term relationships, buyer-seller partnerships and, strategic alliances, to network organization and vertical integration (Webster, 1992). According to Coviello, Brodie and Munro (1997) framework, any step along this continuum "might be relevant to, or practiced by, an organization at a given time" (Coviello and Brodie, 2001, p.386). Following this line of reasoning, repeated and frequent transactions between supplier and buyer "means that the rudiments of trust and credibility are present, which can be the foundations of a relationship." (Webster, 1992, p.8). Research has widely stated that developing relationships between a supplier and its customers is crucial to business (Hansen, 2009; Toms, 2006), because it is related to more 
profitability and is a key source of competitive advantage (Webster, 1992; Weitz and Jap, 1995; Sharma and Sheth, 1997). Other studies illustrate a variety of relational benefits for the marketer, such as relationship quality (Crosby, Evans and Cowles, 1990) and buyer trust (Morgan and Hunt, 1994; Sallee and Flaherty, 2003).

Considering these benefits, it is logical to assume that sellers who have already developed a relationship with professional buyers will be more effective in subsequent sales encounters (Wagner, Klein and Keith, 2003) than in a situation in which no relationship has been developed. Following the normative approach (Macneil, 1980), to identify norms that distinguish discrete exchanges from relational exchanges, Wagner, Klein and Keith (2003, p. 296) conceptualize relational exchanges "as having higher degrees of three norms germane to a personal selling context: solidarity, role integrity, and information exchange." These norms of a relational exchange "imply concern of the partner and should encourage the belief that the seller is acting in the buyer's best interests. Consequently, the buyer may value the information gained from the salesperson, trust in its credibility, and be more influenced by it" (Wagner, Klein and Keith, 2003, p.296). In contrast, in a discrete exchange, the buyer may have more difficulty evaluating the seller's credibility, may be more likely to suspect opportunistic behavior, and ultimately may be more reluctant to risk buying the product. Using simulated sales calls from photocopier salespeople in a field experiment manipulating the relational versus discrete exchange situation according to these norms, Wagner, Klein and Keith's (2003) results support the importance of the buyer-seller relationship by revealing that a professional buyer in a relational exchange with a seller (as opposed to a discrete exchange) evaluates the seller's product more effectively and has more opportunity to consider and choose it for purchase.

This relational advantage in terms of enhanced seller credibility should benefit CSPs more than NCSPs. The rationale is that in the advertising setting, source credibility is lower for comparative ads, but comparative ads with enhanced credibility increase individuals' likelihood to purchase. This supposed moderating influence is in line with Grewal et al.'s (1997) conclusion that enhanced credibility is desirable when the advertising goal is to influence individuals' purchase behavior.

It is also in line with Wagner et al.'s (2001) conjecture concerning the condition under which sharing information about competitive products with the buyer is effective; the condition is that the buyer has to be favorably predisposed to the seller who provides this information. As noted by Michaels, Dubinsky, and Rich (1995), personal factors have also an impact on professional buyers' motivation.

To examine the moderating effect of a preexisting buyer-seller relationship when examining the impact of comparative pitches on new product buying behaviors, we propose a set of three hypotheses. The first two stress the impact of comparative versus noncomparative pitches on new product buying behaviors, respectively, when a buyerseller relationship exists (H1) and when it does not (H2). When a buyer-seller relationship exists, we propose:

H1: CSPs are more likely than NCSPs to generate a new sales order for a new product when a buyer-seller relationship exists.

At the contrary, when a buyer-seller relationship does not exist, we suppose any difference between the two kinds of sales pitches in terms of buying behaviors:

H2: CSPs are not more likely than NCSPs to generate a sales order for a new product when a buyer-seller relationship does not exist.

Finally, focusing on the importance of a preexisting buyer-seller relationship and its relational advantage, regardless of whether the pitches are comparative, we advance:

H3: Regardless of the nature of the sales pitch (comparative vs. noncomparative), the likelihood of sales order for a new product is greater when a buyer-seller relationship exists than when it does not. 


\section{METHODOLOGY}

\section{Study Context}

Sector and Product Description

We conducted our study in the pharmaceutical sector for a brand of dietary supplements targeting menopausal and premenopausal women. All the pharmacists participating in this study knew and had already purchased this brand. The pharmaceutical company was launching, under the same brand name, a new home menopause test that works similarly to a home pregnancy test. The only competitor at that time was a blood test, which required laboratory analysis and medical interpretation. Therefore, the main advantage of this new home menopause test was the ability to perform it at any time and purchase it in a pharmacy with no prescription. In this context, the new home menopause test is the promoted product, and the blood menopause test is the comparison product.

\section{Telesales}

To launch the menopause test, the firm implemented a telephone sales campaign targeting pharmacists to generate initial sales orders to ensure product accessibility to end customers in as many pharmacies as possible. We therefore conducted our experiment within the framework of the telephone sales campaign - an important selling method today (Moncrief and Marshall, 2005). In this context, only the telephone salespersons were able to offer the product (i.e., medical or pharmaceutical representatives could not offer pharmacies access to the test). The sales pitch offered each contacted pharmacist a reduced wholesale price. In addition to the telephone campaign, the sales personnel sent a fax describing the product to each pharmacist in an attempt to strengthen the effectiveness of the operation (Parsons and Vanden Abeele, 1981; Johnson and Meiners, 1987).

\section{Study Design}

A call center belonging to a pharmaceutical wholesale distributor ran the telesales campaign. Its salespeople were directed to contact more than 4,500 pharmacists with an automatic random call system, which assigned to each salesperson either a CSP or an NCSP upon reaching a pharmacist. The CSP explicitly demonstrated the advantages of the new medical menopause test over the traditional test by comparing the main characteristics of the new product (the reliability of the test and ease of use at home) with the competitor's product. The NCSP focused only on the intrinsic reliability of the test and its ease of use without any comparison (see the scripts of the two sales pitches in the Appendix). It should be noted that the CSP is longer ( $25 \%$ more words in the CSP than in the NCSP; see the appendix), which is not an advantage for distance selling.

The study only includes the calls in which the salesperson was able to make a presentation to the pharmacist ( $n=4,228$ pharmacists). Of these 4,228 pharmacists, 2,822 regularly order their products mainly through the wholesale distributor that implemented the telesales campaign, which we term the "reference wholesaler" (i.e., the wholesaler with which a regular relationship exists). In contrast, for the remaining 1,406 pharmacists, the wholesaler implementing the telesales campaign is not their reference wholesaler. In other words, these pharmacists did not have a regular relationship with the firm and mainly ordered their products through another wholesale distributor.

At the beginning of each telephone call, the salesperson stated, "I'm Mr./Ms. from W (the name of the wholesaler implementing the telesales campaign)." For the 2,822 pharmacists already having regular exchanges with this wholesaler, mentioning its name activated the existing relationship between the wholesaler and the pharmacist. For the remaining 1,406 pharmacists who do not have regular exchanges with this wholesaler, mentioning its name did not activate any existing relationship. Approximately half of both groups of pharmacists received NCSPs, and the other half received CSPs (see Table 1). Each salesperson contacted pharmacists from both groups randomly and randomly received directions about which type of presentation to use each time the computerized call system made contact with a pharmacist. 
Table 1. Number of pharmacists as a function of sales pitch type and wholesaler-pharmacist relationship

\begin{tabular}{lccc}
\hline & NCSP & CSP & Total \\
\hline Pharmacists not having a regular relationship with the wholesaler & 718 & 688 & 1,406 \\
Pharmacists having already a regular relationship with the wholesaler & 1,350 & 1,472 & 2,822 \\
Total & 2,068 & 2,160 & 4,228 \\
\hline
\end{tabular}

Note that the context of telesales calls, rather than a more classic form of personal selling such as pharmaceutical representatives, is particularly suitable for this quasi-experimental study. It controls the presentation - "the main body of the sales call" (Moncrief and Marshall, 2005) - effectively (i.e., the script appears on a computerized telesales screen, and the salesperson simply administers it), allowing us to make more confident causal inferences about the hypothesized relationships (Wagner, Klein and Keith, 2003). It also enables each salesperson to contact a large number of clients using either a CSP or an NCSP.

\section{RESULTS}

To determine whether CSPs are more likely to generate an initial sales order than NCSPs when a buyerseller relationship exists (H1), we ran a logistic regression. In line with Irwin and McClelland (2001), we first used the following Boolean coding for the two independent variables: SP $(1=$ comparative pitch, $0=$ noncomparative pitch) and $\mathrm{W}(0=$ existence of a regular relationship between the wholesaler and the pharmacist, $1=$ otherwise). Table 2 presents the results of this logistic regression.

Table 2. Logistic regression results of a new product sales order on type of sales pitch and wholesaler

\begin{tabular}{lccccc}
\hline \multicolumn{1}{c}{ Variables } & $\boldsymbol{\beta}$ & Standard Error & Wald & $\boldsymbol{p}$ & $\mathbf{E x p}(\boldsymbol{\beta})$ \\
\hline $\begin{array}{l}\text { Sales Pitch (SP) } \\
\text { Wholesaler (W) }\end{array}$ & .685 & .106 & 42.008 & .000 & .900 \\
$\begin{array}{l}\text { Sales Pitch } \\
\text { x Wholesaler }\end{array}$ & -.851 & .185 & 21.149 & .984 & .427 \\
$\begin{array}{l}\text { (SP x W) } \\
\text { Constant }\end{array}$ & -.785 & .263 & 8.899 & .003 & .456 \\
\hline
\end{tabular}

Notes: $\mathrm{n}=4,228$

When a regular relationship exists between the wholesaler and the pharmacist, the probability that the pharmacist orders the promoted new product is given by the following equation:

$\operatorname{prob}(\operatorname{order}=1)=\frac{e^{0.685 S P-0.851 W-0.785 S P * W-2.007}}{1+e^{0.685 S P-0.851 W-0.785 S P * W-2.007}}$

The coefficient that expresses the effect of the comparative sales presentation on an initial sales order for the promoted product equals .685 (significantly different from 0 at $p<.001$ ). The odds ratio of a new product sales order to a client of the reference wholesaler is multiplied by a factor of nearly 2 (estimated odds ratio: $\operatorname{Exp}(\beta)=$ 1.984). Among pharmacists in a regular relationship with the wholesaler, the likelihood of a new product sales order in response to a CSP is almost double (21.1\%) that of a NCSP $(11.9 \%)$. Thus, the results offer compelling support for $\mathrm{H} 1$.

To test the effect of the type of sales pitch when there is no regular relationship between the wholesaler and the pharmacist, we alternate the coding of the supposed moderating variable (Irwin and McClelland, 2001). Running the same logistic regression (except that we inverted the coding of the wholesaler variable; i.e., $0=$ no regular relationship between the wholesaler and the pharmacist and $1=$ existence of a regular relationship), we achieve the results presented in Table 3. 
Table 3. Logistic regression results of a new product sales order on type of sales pitch and wholesaler

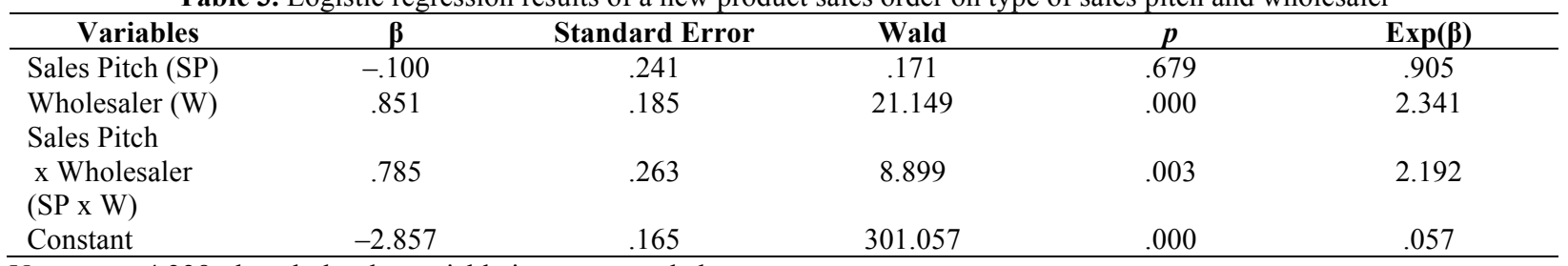

Notes: $n=4,228$; the wholesaler variable is reverse-coded.

Thus, we estimate the likelihood of a successful sales order from a pharmacy having no regular relationship with the wholesaler with the following equation:

$\operatorname{prob}($ order $=1)=\frac{e^{-0.100 S P+0.851 W+0.785 S P * W-2.857}}{1+e^{-0.100 S P+0.851 W+0.785 S P * W-2.857}}$

In this case, the effect of the type of sales pitch on an initial sales order for the promoted product is not significant (coefficient $\beta=-.100, p=.679$ ). That is, in contrast to the results for pharmacists having a regular relationship with the wholesaler, we observed no difference with regard to the type of pitch the salesperson used when the wholesaler had no regular relationship with the pharmacist. The likelihood of an initial order remains less than $5.5 \%$, regardless of the type of sales pitch used, in support of H2. The wholesaler-pharmacist relationship moderates the effects of a CSP on the likelihood of an initial order of the promoted product. Figure 1 displays the percentages of pharmacists ordering the promoted product as a function of sales pitch type and wholesalerpharmacist relationship.

Figure 1. Percentages of pharmacists ordering the promoted new product as a function of sales pitch type and wholesaler-pharmacist relationship

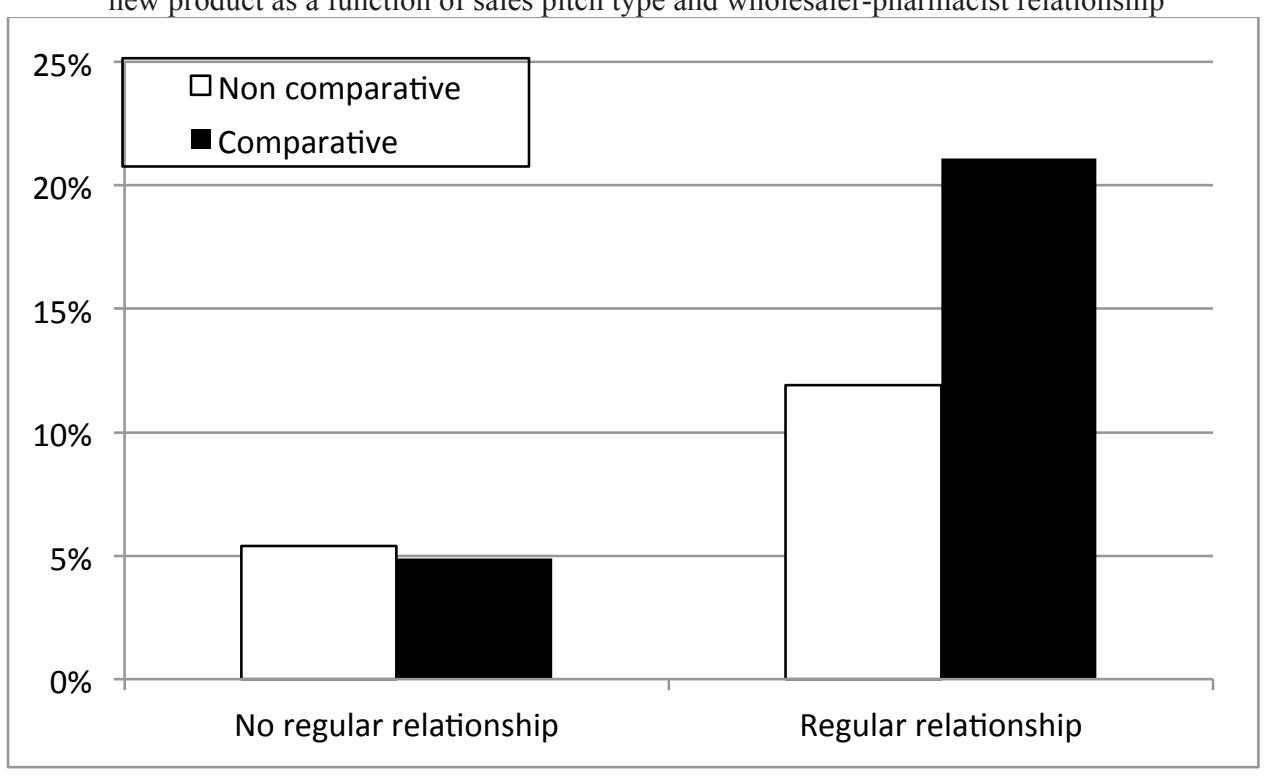

In addition, the effect of the existence of a regular relationship between the wholesaler and the pharmacist is noteworthy. These results show that the existence of a regular relationship between the wholesaler and the pharmacist has a positive effect on the likelihood of a new product sales order, regardless of type of sales pitch. As the results displayed in Figure 2 show, such a regular relationship increases the likelihood of a new product sales order from $4.9 \%$ to $21.1 \%(p<.001)$ for CSPs and from $5.4 \%$ to $11.9 \%(p<.001)$ for NCSPs. 
Figure 2. Percentages of pharmacists ordering the promoted

new product as a function of wholesaler-pharmacist relationship and sales pitch type

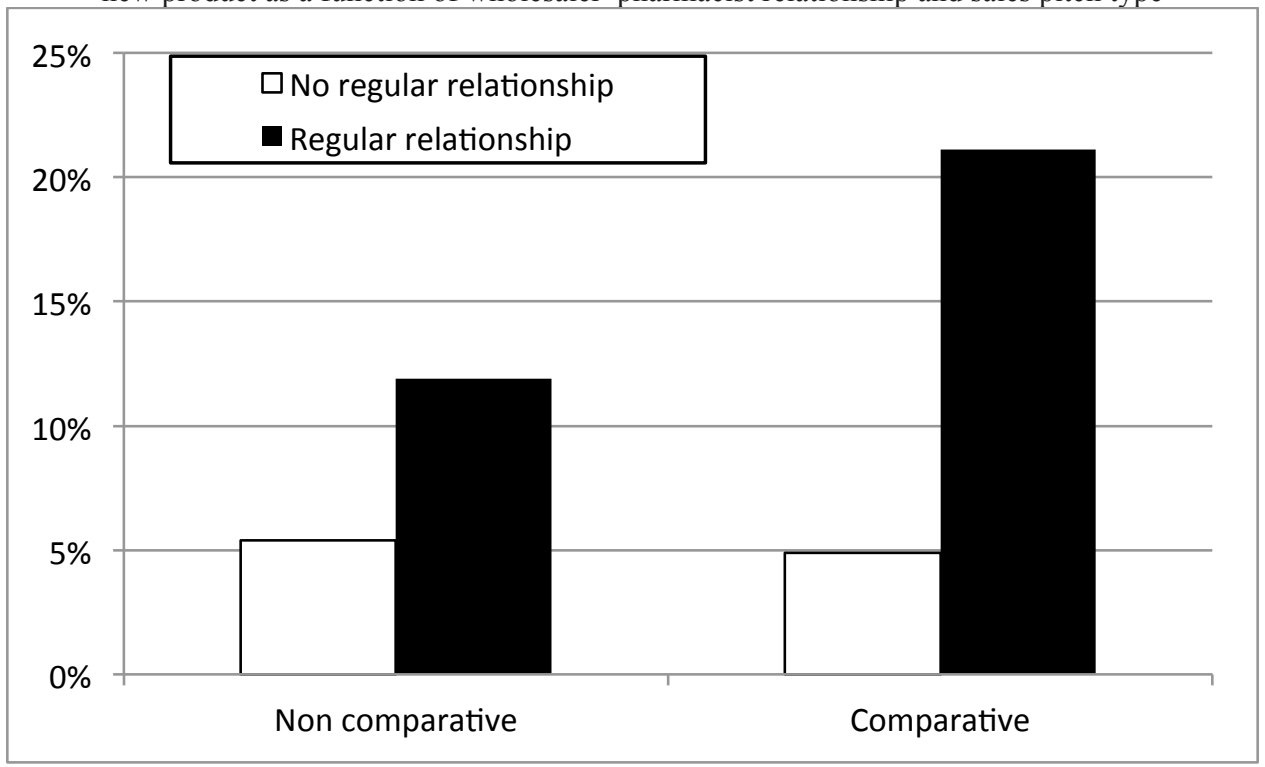

The odds ratio of a sales order from a pharmacist having a regular relationship with the wholesaler is multiplied by a factor greater than 5 (cf. $\beta=1.635, p<.001$, estimated odds ratio $\operatorname{Exp}(\beta)=5.132$ ) for CSPs and greater than 2 (cf. $\beta=.851, p<.001$, estimated odds ratio $\operatorname{Exp}(\beta)=2.341$ ) for NCSPs. As H3 hypothesizes, our findings are in accordance with the benefits of buyer-seller relationships for selling effectiveness that the literature indicates (e.g., Wagner, Klein and Keith, 2003).

\section{DISCUSSION AND CONCLUSION}

The main contribution of this field research pertains to the efficacy of CSPs in terms of actual buying behavior towards a new product as well as the boundary conditions of CSPs efficacy. To our knowledge, this study is among the first in the selling context. We show that a CSP is more likely to generate a sales order for a new product than an NCSP but that this positive effect is constrained to when a regular relationship between the buyer and the seller exists. Although the CSP does not have any negative effects, its potential to enhance salespeople's new product selling effectiveness appears to depend on the existence of a buyer-seller relationship.

Taken together, our findings emphasize the moderating influence of a buyer-seller relationship and its resulting benefits when launching a new product. As a corollary, these findings illustrate the boundary conditions of effectiveness of different types of sales pitches for product launches. Obtained in a naturalistic setting, these findings contribute to fill the gap of empirical support regarding the effectiveness of CSPs for product launches in a personal selling context on actual purchase behavior (in contrast to other research, which tests purchase intentions). Moreover, this research establishes the important moderating effect of the relationship between CSPs and selling effectiveness when launching a new product. More generally, these findings highlight the importance of the nature of the sales pitches for improving new product selling effectiveness and contribute to the new product launch and performance literature. They support also the theoretical perspective that the relationship between selling behaviors and selling effectiveness is contingent on various factors (Weitz, 1981; Wagner, Klein and Keith, 2001).

By showing that CSPs need an established buyer-seller relationship to generate greater efficacy for launching a new product than NCSPs, this research contributes to the comparative advertising literature as well. This literature indicates that enhanced credibility should benefit comparative ads more than noncomparative ads to increase consumers' likelihood to purchase (Grewal et al., 1997). Our research suggests that an established buyerseller relationship, and its resulting relational advantage in terms of sellers' enhanced credibility, interact with the CSP versus NCSP efficacy. Moreover, extant research shows that CSPs can be more effective than NCSPs in terms 
of behavioral outcomes. These findings go beyond previous research, which has typically operationalized conation as purchase intentions and not as actual purchase behaviors.

As a side contribution, by showing that the likelihood of a new product sales order is significantly greater when a buyer-seller relationship already exists, regardless of the type of sales pitch used, the results support the direct influence of the relational advantage of buyer-seller relationships on salespeople's effectiveness (Wagner, Klein and Keith, 2003). This direct influence on selling effectiveness is often assumed but has never been empirically evidenced, especially with regard to actual buying behavior. In addition, our findings extend previous findings by showing the influence of the buyer-seller relationship on salespeople's effectiveness even when selling a new product in a new-buy situation. As Wagner, Klein and Keith (2003, p.301) note, "Conventional wisdom speaks of the increased opportunities that exist for 'out' suppliers in new-buy purchases."

From a managerial perspective, this research offers compelling implications. Our results suggest that CSPs can represent a potential tool for increasing selling effectiveness for product launch. The findings should encourage managers and salespeople to consider CSPs when launching a new product, especially when a buyer-seller relationship exists. In this respect, this study offers an illustration of how they might function in the context of a telesales campaign. When the condition of an established buyer-seller relationship is not fulfilled, the positive effect of CSPs no longer manifests, indicating that using CSPs is not enough to expect more positive behavioral outcomes. In this case, although the CSP has never been less effective than the NCSP, managers might be well advised to avoid using CSPs, because comparative claims can lead to negative effects in terms of awareness of competitors' products or source believability, as research in the advertising setting shows (Grewal et al., 1997; Stevenson and Swayne, 1988).

By showing the moderating role of an established buyer-seller relationship, the results also highlight the importance of the type of relationship existing between the seller and the buyers as a segmentation variable for the design of sales pitches. Finally, the findings emphasize the key benefit of developing well-established relationships with the buyers to achieve higher selling effectiveness, regardless of the type of sales pitches used.

Note that caution is warranted before generalizing these early results. Although derived from a quasiexperimental study carried out with real sellers and buyers in actual new product sales order situations, our results are subject to several limitations that also suggest some promising research avenues.

First, we test the influence of CSPs in restrictive conditions: a telephone-based sales presentation to pharmacists, with the goal of selling a new product that offers substantial benefits to the end consumer compared with a reference product that actually is linked to another category and cannot be marketed by pharmacists. Would the results be similar if the CSP did not involve a really new product offering a high relative advantage but instead a less innovative product similar to an existing product but offering product improvements? If the promoted product were not a really new product, one might expect that the well-established buyer-seller relationship condition (and its benefits in terms of perceived credibility) would be less important or even not required at all. However, even in the case of product improvement, would the claimed improvement and relative advantage be perceived as credible without the existence of a buyer-seller relationship? According to the advertising literature, comparative ads require credibility enhancers to outperform noncomparative ads on intention to purchase the promoted product (Grewal et al., 1997). Following this line of reasoning, an interesting contingency linked to our findings is the question of under which conditions (if any) CSPs would require no buyer-seller relationship to be more effective for product launch than NCSPs. From this perspective, additional research should consider two products that are less different (in terms of relative advantage) offered on the market by two different brands; these products might even be provided by the same distributor (wholesaler).

Even if a clear dichotomous pattern of contemporary marketing practices of business-to-business and consumer firms fails to emerge (Coviello and Brodie, 2001), the business-to-business professional setting of our study might be perceived as another limitation for our findings. However, according to Wagner, Klein and Keith (2003), the established buyer-seller relationship's positive effect on product evaluation, consideration, and choice is stronger for novice buyers than for expert buyers. Therefore, the buyer-seller relationship moderating effect found in this study might also hold for buyers with less expertise as consumers. Furthermore, we test the superiority of 
CSPs in the frame of a wholesaler-retailer relationship. Further research should test the generalizability of our results across other samples of buyers and consumers.

Another limitation for our findings concerns the distinction "no regular buyer-seller relationship vs. regular buyer-seller relationship". As pointed out, buyer-seller relationships are more complex and further research should investigate the full range of marketing relationships as outlined in the literature (Webster, 1992; Coviello, Brodie and Munro', 1997). Moreover and as a corollary issue, we do not measure the level of credibility that buyers perceive toward a seller but instead presume greater credibility between a pharmacist and its reference wholesale distributor. Even if the literature usually agrees on seller's enhanced credibility as a result of an existing buyer-seller relationship, further research should measure the seller's perceived credibility to examine its supposed role in the efficacy of comparative sales pitches on new product sales.

Finally, to gain external validity, further research should continue to test the effectiveness of CSPs against NCSPs for product launch, using goods that are more comparable and/or services that are accessible through a single distribution channel and promoted by actors whose sales behavior can be controlled. The limited information available about each party in a relationship hinders adequate assessments of the possible influence of other potential contingency characteristics in the dyad formed by the seller and potential buyer. The type of sales presentation is just one factor among many that may affect selling effectiveness.

Although investigation of the aforementioned issues and other contingencies is important, the findings of this research highlight the potential value of CSPs for improving personal selling effectiveness when launching a new product as well as the moderating role of established buyer-seller relationships. Consequently, this research is a first step for research into CSP effects to gain a better understanding of their boundary selling effectiveness.

\section{AUTHOR INFORMATION}

Christian Dianoux (Ph.D., University of Nancy, France) is Associate Professor of Marketing and a member of the research group in marketing of the CEREFIGE Research Center at the University of Lorraine. His research interests include persuasive communication, especially comparative and international advertising. E-mail: christian.dianoux@univ-lorraine.fr

Jean-Luc Herrmann (Ph.D., University of Nancy, France) is Professor of Marketing and Head of the research group in marketing of the CEREFIGE Research Center at the University of Lorraine, France. His research interests focus on persuasive communication, especially on advertising and sponsorship effects.

Ridha Chakroun is a part-time Assistant Professor of Marketing at IPAG Business School, France. He spent several years as a marketing and sales director in various pharmaceutical companies. He received an MSc in social psychology as well as in business administration and also holds an MD from University of Paris and PhD from University of Nice. His research focuses on social and human resources marketing.

Sandrine Heitz-Spahn is an Assistant Professor of Marketing at the University of Lorraine, France. She holds an MSc in business administration from the EM Strasbourg Business School, University of Strasbourg, France, and a $\mathrm{PhD}$ from the University of Bourgogne, France. Her work concentrates on multichannel consumer behavior.

\section{REFERENCES}

Barry, T. E. (1993). "Comparative advertising: what have we learned in two decades?", Journal of Advertising Research, Vol. 33 No. 2, pp. 19-29.

Barry, T. E., \& Tremblay, R. L. (1975). "Comparative advertising: perspectives and issues”, Journal of Advertising, Vol. 4 No. 4, pp. 15-20.

Beard, F. K. (2013). "Practitioner Views of Comparative Advertising: How Practices Have Changed in Two Decades", Journal of Advertising Research, Vol. 53 No. 3, pp. 1-17.

Chang, C. (2007). "The relative effectiveness of comparative and noncomparative advertising", Journal of Advertising, Vol. 36 No. 1, pp. 21-35. 
Chen, C.-W., Shen, C.-C. \& Chiu, W.-Y. (2007). "Marketing communication strategies in support of product launch: An empirical study of Taiwanese high-tech firms", Industrial Marketing Management, Vol. 36 No. 8, pp. 1046-1056.

Coviello, N. E. \& Brodie, R. J. (2001). "Contemporary marketing practices of consumer and business-to-business firms: how different are they?”, Journal of Business and Industrial Marketing, Vol. 16 No. 5, pp. 382-401.

Coviello, N. E., Brodie, R. J. \& Munro, H. J. (1997). "Understanding Contemporary Marketing: Development of a Classification Scheme", Journal of Marketing Management, Vol. 13 No. 6, pp. 501-522.

Crosby, L. A., Evans, K. A. \& Cowles, D. (1990). "Relationship quality in services selling: an interpersonal influence perspective", Journal of Marketing, Vol. 54 No. 3, pp. 68-81.

Demirdjian, Z. S. (1983). "Sales effectiveness of comparative advertising: An experimental field investigation", Journal of Consumer Research, Vol. 10 No. 3, pp. 362-364.

Dhebar, A. (1995). "Complementarity, Compatibility, and Product Change: Breaking with the Past?” Journal of Product Innovation Management, Vol. 12 No. 2, pp. 136-152.

Dröge, C. (1989). "Shaping the route to attitude change: central versus peripheral processing through comparative versus noncomparative advertising”, Journal of Marketing Research, Vol. 26 No. 2, pp. 193-204.

Dwyer, F. R., Schurr, P. H. \& Oh, S. (1987). "Developing buyer-seller relationships", Journal of Marketing, Vol. 51 No. 2, pp. 11-27.

Golden, L. L. (1979). “Consumer reactions to explicit brand comparisons in advertisements”, Journal of Marketing Research, Vol. 16 No. 4, pp. 517-532.

Gotlieb, J. B. \& Sarel D. (1991). "Comparative advertising effectiveness: The role of involvement and source credibility", Journal of Advertising, Vol. 20 No. 1, pp. 38-45.

Grewal, D., Kavanoor, S., Fern, E. F., Costley, C. \& Barnes, J. (1997). “Comparative versus noncomparative advertising: a meta-analysis", Journal of Marketing, Vol. 61 No. 4, pp. 1-15.

Guiltinan, J. P. (1999). "Launch Strategy, Launch Tactics, and Demand Outcomes", Journal of Product Innovation Management, Vol. 16 No. 6, pp. 509-529.

Hansen, J. M. (2009). "The evolution of buyer-supplier relationships : an historical industry approach", Journal of Business and Industrial Marketing, Vol. 24 No. 3/4, pp. 227-236.

Holak, S. L. \& Lehmann, D. R. (1990). "Purchase Intentions and the Dimensions of Innovation: An Exploratory Model”, Journal of Product Innovation Management, Vol. 7 No. 1, pp. 59-73.

Hsieh, M. H., Blower, K., Li, X., Jain, S. P. \& Posavac, S. S. (2012). “Comparative advertising research”, in Posavac S. S. (Ed.), Cracking the code: Leveraging consumer psychology to drive profitability, M. E. Sharpe, Armonk, NY, pp. 132-157.

Irwin, J. R. \& McClelland, G. H. (2001). "Misleading heuristics and moderated multiple regression models", Journal of Marketing Research, Vol. 38 No. 1, pp. 100-109.

Johnson, E. M. \& Meiners, W. J. (1987). “Telemarketing: trends, issues, and opportunities”, Journal of Personal Selling and Sales Management, Vol. 7 No. 3, pp. 65-68.

Lee, Y. \& O’Connor, G.C. (2003). “The Impact of Communication Strategy on Launching New Products: The Moderating Role of Product Innovativeness", Journal of Product Innovation Management, Vol. 20, pp. 421.

MacArthur, K. \& Cuneo, A. Z. (2007). "Why big brands are getting into the ring”, Advertising Age, Vol. 78 No. 21 , p. 6.

MacInnis, D. J., Moorman, C. \& Jaworski, B. J. (1991). "Enhancing and measuring consumers' motivation, opportunity, and ability to process brand information from ads", Journal of Marketing, Vol. 55 No. 4, pp. 32-53.

Macneil, I. R. (1980). The New Social Contract: An Inquiry into Modern Contractual Relations, Yale University Press, New Haven, CT.

Meyers-Levy, J. \& Malaviya, P. (1999). “Consumers' processing of persuasive advertisements: an integrative framework of persuasion theories", Journal of Marketing, Vol. 63 No. 4, pp. 45-60.

Michaels R. E., Dubinsky A. J., \& Rich G. A. (1995). An Empirical Investigation of Components of Industrial Buyer Motivation, Journal of Business to Business Marketing, Vol. 2 No. 2, pp. 5-35.

Miniard, P. W., Rose, R. L., Barone, M. J. \& Manning, K. C. (1993). “On The Need For Relative Measures When Assessing Comparative Advertising Effects”, Journal of Advertising, Vol. 22 No. 3, pp. 41-57.

Moncrief, W. C. \& Marshall, G. W. (2005). "The evolution of the seven steps of selling", Industrial Marketing Management, Vol. 34 No. 1, pp. 13-22. 
Morgan, R. M. and Hunt, S. D. (1994). "The commitment-trust theory of relationship marketing", Journal of Marketing, Vol. 58 No. 3, pp. 20-38.

Muehling, D. D., Stoltman, J. J. \& Grossbart, S. (1990). "The impact of comparative advertising on levels of message involvement", Journal of Advertising, Vol. 19 No. 4, pp. 41-50.

Ostlund, L. E. (1974). "Perceived Innovation Attributes as Predictors of Innovativeness", Journal of Consumer Research, Vol. 1 No. 2, pp. 23-29.

Parsons, L. J. \& Abeele, P. V. (1981). “Analysis of sales call effectiveness”, Journal of Marketing, Vol. 18 No. 1 , pp. $107-113$.

Pechmann, C. \& Esteban, G. (1994). "Persuasion processes associated with direct comparative and noncomparative advertising and implications for advertising effectiveness", Journal of Consumer Psychology, Vol. 2 No. 4, pp. 403-432.

Pechmann, C. \& Stewart, D. W. (1990). "The effects of comparative advertising on attention, memory, and purchase intentions", Journal of Consumer Research, Vol. 17 No. 2, pp. 180-191.

Petty, R. E., Cacioppo, J. T. \& Schumann, D. (1983). "Central and peripheral routes to advertising effectiveness: The moderating role of involvement", Journal of Consumer Research, Vol. 10 No. 2, pp. 135-146.

Putrevu, S. \& Lord, K. R. (1994). "Comparative and noncomparative advertising: attitudinal effects under cognitive and affective involvement conditions", Journal of Advertising, Vol. 23 No. 2, pp. 77-90.

Rose, R. L., Miniard, P. W., Barone, M. J., Manning, K. C. \& Till, B. D. (1993). "When persuasion goes undetected: The case of comparative advertising”, Journal of Marketing Research, Vol. 30 No. 3, pp. 315-330.

Sallee, A. \& Flaherty, K. (2003). "Enhancing salesperson trust: an examination of managerial values, empowerment, and the moderating influence of sbu strategy", Journal of Personal Selling and Sales Management, Vol. 23 No. 4, pp. 299-310.

Shao, A. T., Bao, Y. \& Gray, E. (2004). "Comparative advertising effectiveness: A cross-cultural study", Journal of Current Issues and Research in Advertising (CTC Press), Vol. 26 No. 2, pp. 67-80.

Sharma, A. \& Sheth, J. N. (1997). "Relationship marketing: An agenda for inquiry", Industrial Marketing Management, Vol. 26 No. 2, pp. 87-89.

Stevenson, T. H. \& Swayne, L. E. (1988). "Guidelines for comparative advertising in industrial trade publications", Journal of Business and Industrial Marketing, Vol. 3 No. 1, pp. 37-44.

Swinyard, W. R. (1981). "The interaction between comparative advertising and copy claim variation", Journal of Marketing Research, Vol. 18 No. 2, pp. 175-186.

Thompson, D. V. \& Hamilton, R. W. (2006). “The effects of information processing mode on consumers' responses to comparative advertising", Journal of Consumer Research, Vol. 32 No. 4, pp. 530-540.

Toms Lisa C (2006). "Conflict management strategies and manifest conflict: do they matter in buyer/seller relationship”, Journal of Applied Business Research, Vol. 22 No. 3, pp. 96-107.

Veryzer, R.W. Jr (1998). "Key Factors affecting Customer Evaluation of Discontinuous New Products", Journal of Product Innovation Management, Vol. 15, pp. 136-150.

Wagner, J. A., Klein, N. M. \& Keith, J. E. (2001). "Selling strategies: The effects of suggesting a decision structure to novice", Journal of the Academy of Marketing Science, Vol. 29 No. 3, pp. 290-306.

Wagner, J. A., Klein, N. M. \& Keith, J. E. (2003). "Buyer-seller relationships and selling effectiveness: the moderating influence of buyer expertise and product competitive position", Journal of Business Research, Vol. 56 No. 4, pp. 295-302.

Webster, F.E. (1992). "The changing role of marketing in the corporation”, Journal of Marketing, Vol. 56 No. 4, pp. $1-17$.

Weitz, B. A. \& Jap, S. D. (1995). "Relationship Marketing and Distribution Channels", Journal of the Academy of Marketing Science, Vol. 23 No. 4, pp. 305-320.

Weitz, B. A. (1978). "Relationship between salesperson performance and understanding of customer decision making”, Journal of Marketing Research, Vol. 15 No. 4, pp. 501-516.

Weitz, B. A. (1981). "Effectiveness in sales interactions: A contingency framework", Journal of Marketing, Vol. 45 No. 1, pp. 85-103.

Wilkie, W. M. \& Farris, P. W. (1975). "Comparison advertising: problems and potential”, Journal of Marketing, Vol. 39 No. 4, pp. 7-15. 


\section{APPENDIX}

\section{Extract from the introduction script used for both presentations}

Hello, I'm Mr./Ms. X from "W" ...

[i.e., for 2,822 pharmacists, the wholesaler with which they already have a regular relationship; for the remaining 1,426 pharmacists, there is no regular relationship with this wholesaler]

I'm contacting you regarding the launch of a new product in the XX (name of the brand of the pharmaceutical company) range, $\mathrm{XX}{ }^{\circledR}$ Test Ménopause, which is a home menopause test ... have you heard of it?

\section{Extract from the CSP script (181 words in the original French version):}

The XX® range, famous for its food supplements that naturally manage menopause, is expanding with a new product, the $\mathrm{XX}{ }^{\circledR}$ Test Ménopause. This home diagnosis kit allows your customers to test whether they are menopausal or not without having to undergo the blood test that is usually used for this diagnosis. It is as easy to use as a pregnancy test. The reliability of the urinary level of FSH is greater than $99 \%$. It is therefore identical to the blood test, but with better result interpretations because each pack of XX® Test Ménopause contains two tests that should be taken 5 days apart. The other advantage of XX® Test Ménopause compared to the blood test is that it is much more convenient because there is no need to go to a lab and have a blood test. It also allows quick and easy access to results while being very simple to use, which makes it easy to recommend ... And to help you meet your customers' requirements and avoid any stock issues, W [the wholesaler] offers you the best conditions...

[The sections in bold illustrate the comparative presentation.]

\section{Extract from the NCSP script (145 words in the original French version):}

The $\mathrm{XX} \otimes$ range, known for its food supplements to naturally manage menopause, is expanding with a new product, the XX® Test Ménopause. This is a home diagnosis kit that allows your customers to find out whether they are menopausal or not. It is as easy to use as a pregnancy test. The reliability of the urinary level of FSH is greater than $99 \%$, and result interpretation is very good because each pack of XX® Test Ménopause contains two tests that should be taken 5 days apart. Also, $\mathrm{XX}{ }^{\circledR}$ Test Ménopause is very convenient for your female customers and gives them quick and easy access to results while being very simple to use, which makes it easy to recommend... And to help you meet your customers' requirements and avoid any stock issues, W [the wholesaler] offers you the best conditions...

[For both scripts, the next section included a commercial offer for either a six-box presentation case, with a reduction for purchasing the product that applied to the current call only, or the possibility of ordering the product individually)] 